\title{
Gender Discrimination and Sex-Ratio Imbalance: A Qualitative Analysis
} Bijayalaxmi Nanda ${ }^{1}$, Nupur Ray ${ }^{2}$

${ }^{1}$ Acting Principal, Miranda House, University of Delhi and Associate Professor, Department of Political Science, Miranda House, University of Delhi; ${ }^{2}$ Assistant Professor, Department of Political Science, Kamala Nehru College, University of Delhi)

\begin{tabular}{|c|c|c|c|c|c|c|c|c|}
\hline Abstract & Introduction & Methodology & Results & Conclusion & References & Citation & \multicolumn{2}{|c|}{ Tables / Figures } \\
\hline \multicolumn{9}{|c|}{ Corresponding Author } \\
\hline \multicolumn{8}{|c|}{$\begin{array}{l}\text { Dr. Bijayalaxmi Nanda, Acting Principal, Miranda House, University of Delhi and Associate } \\
\text { Professor, Department of Political Science, Miranda House, University of Delhi. } \\
\text { E Mail ID: bijayalaxmi.nanda@mirandahouse.ac.in }\end{array}$} & 回部回 \\
\hline
\end{tabular}

\section{Citation}

Nanda B, Ray N. Gender Discrimination and Sex-Ratio Imbalance: A Qualitative Analysis. Indian J Comm Health. 2020;32(4):746-750. https://doi.org/10.47203/IJCH.2020.v32i04.025

Source of Funding: The paper has emerged from an ongoing Research Study supported by the Indian Council of Social Science Research ( ICSSR) Conflict of Interest: None

\section{Article Cycle}

Received: 01/12/2020; Revision: 12/12/2020; Accepted: 23/12/2020; Published: 31/12/2020

This work is licensed under a Creative Commons Attribution 4.0 International License.

\section{Abstract}

The article strives to engage with the notion of gender discrimination at birth. It critically examines the various trends in the Sex Ratio at Birth in order to explore the intensification of its masculinization. Gender- biased sex selection or the practice of sex determination followed by sex-selective abortion in India is considered to be the main reason for this masculinization. Decennial Census since 1991 has shed light on this through its child sex ratio data. Other survey data which capture this include the National Family Health Survey. Scholars, policy-makers, demographers and health practitioners have closely examined this form of discrimination by delving into both qualitative and quantitative analysis. The government of India has unfurled many policies, programmes and laws to counter this imbalance. However, the ratios continue to reveal severe imbalances with passage of time. Apart from the Pre-conception and Pre-natal Diagnostic Techniques (Prohibition of Sex Selection Act) 1994 we have the Beti Bachao Beti Padhao scheme which was initiated in 2014. The scheme is a holistic one bringing about a tri ministerial convergence of the Ministry of Health and Family Welfare, Ministry of Education and Ministry of Women and Child Development to work on the issue. The approach of the scheme is a community approach falling largely within the rubric of enabling community health practices and participation. The paper draws on both the trends in the Sex Ratio at Birth and other data enriching it by voices from the field from districts of Haryana and Uttar Pradesh where the decline is one of the worst. It contextualizes the Beti Bachao Beti Padhao scheme in this regard in order to arrive at a conclusion of what has improved in terms of numbers as well as attitudes or mindsets. It finally makes suggestions for the way forward in terms of countering gender discrimination at birth and bringing about an egalitarian society by emphasizing on the value of girl-child and women.

\section{Keywords}

Gender Discrimination; Sex-Ratio; Beti Bachao Beti Padhao

\section{Introduction}

India stands at crossroads of paradoxical demographic trends due to a complex intersecting of socio-cultural and economic determinants in a patriarchal society. The overall sex ratio (OSR) at nationwide (the number of females per 1000 males) in 2011 Census has improved by seven percentage points to 940 against 933 in census of 2001. This is the highest sex ratio at the national level since census of 1971 and marginally lower than 1961. 
However, it is the increasingly masculinized and imbalanced child sex ratio that continues to be an issue of concern for feminists, demographers and policy analysts. The provisional data in 2011 Census showed that the child sex ratio ( 0 to 6 years) came down to 914 females per 1000 males against 927 in 2001 (1). It showed a continuing preference for male children to female children in the last decade

Amartya Sen (2) in his pivotal article in 1990, initiated the much-needed debate around 'missing women' suggesting that millions of women were missing from the total populations of many countries in Asia. In others words, these 'missing women' should have survived calculated on the basis of demographic trends in comparison to other countries, but are missing from the total count. He also noted that the female sex ratio in India, China and South Korea are deteriorating whereas there is a marginal improvement in overall sex ratio for females in these countries. Though a part of response to his argument has been to contest his method and estimate by different scholars like Ansley Coale (3), the issue certainly gained a wider and urgent attention of the world.

The other point of contention has been the method to calculate gender based demographic trends and conclusions drawn. The Child Sex Ratio (CSR) is a robust indicator measuring gender discrimination among younger cohorts. Besides, Sex Ratio at Birth (SRB) has also captured attention among demographers following the widespread occurrence of sex selective abortions and with the spread of ultrasound and amniocentesis leading to millions of missing female births. However, whether SRB is a real indicator of pre-natal sex selection, has been up for debate. Dubuc and Sivia (4) recently argued that SRB may not be a reliable indicator to unmask prenatal sex selection. Rather sex selection propensity adjusted to the effects of fertility bias better explains the trajectory of sex selection practices in India.

The highly masculinized child sex ratio of Indian population has been an issue of concern and deliberations. Number of studies and analysis have looked at various numerical and interpretive dimensions of unravelling implicit gender discrimination expressed through strong preference with strong regional variations $(2,5,6,7,8)$. These studies have exposed numerous factors ranging from economic and security constraints of raising a girl child to strong son preference embedded in patrilineal traditions and insecurities of being 'looked after' in old age.

There is also a growing acceptance to number of other independent data sets to estimate child sex ratio at birth. These include the Civil Registration System (CRS), Sample Registration System (SRS), decennial Census, and National Family Health Surveys (NFHS).

The useful and most reliable source of the data is the census, which undertakes a complete enumeration of people across the country, barring the fact that estimates for some of the smaller states and politically/territorially charged states are subject to uncertainty $(9,10)$. Since 1981 , the census has included questions on 'births last year' to married women and on 'the number of children ever born' as well as 'the number of surviving children' to ever married women. This information is tabulated by sex of children and age of women which allows us to compute the sex ratio of births last year and of all births to women.

Apart from census, numerous other large-scale household sample surveys conducted at pan Indian level that cater to variables of socio-economic interests, furnish information about such demographics through crossing the age group.

Under the Civil Registration System (CRS), due to mandatory registration of births and deaths mandated under the Registration of Births and Deaths Act 1969, the data is seen as a comprehensive one indicating Sex Ratio at Birth (SRB) for the country. However, since the registration itself could be based on sex-selective preferences, it does not give account of girl children who 'should have been part of this data'. (1)

The SRS has been providing estimates of fertility and mortality on a regular basis since 1970 . The SRS is a dual record system with continuous registration and half-yearly retrospective surveys that are reconciled and corrected. As the name suggests, since the data set provides registration of a sample in a geographical unit, and a three-year estimate, instead of a yearly one, the method has its limitations. (1) CSR can also be disaggregated to district level with the National Family Health Survey (NFHS) which covered 601,509 households in its last survey in 2015-16. The NFHS is the demographic and health survey for India with four rounds so far. In contrast, with the National Sample Survey (NSS) and India Human Development Survey (IHDS), the level of disaggregation is limited only up to the state as the 
household coverage is not as extensive as the NFHS.

The NSS 68th round (2011-12) covered 100,957

households while the coverage of IHDS in 2011-12 was only 42,152 . On the other hand, the census covers every household in the country culling information of every child born during the years 2003 and 2009 as its 0-6 age cohort in its 2011 dataset. Hence the granularity of the census data is much finer and reducible at the village/ward level.(11)

Though there may be variations in methods of calculations and therefore in estimates drawn, all kinds of surveys have indicated increasingly masculinized trends in child sex ratio in the last few decades with demographers, feminists, civil society organizations, and policy makers having delved upon a range of socio-economic, cultural and regional factors responsible for the imbalance.

Social scientists and activists have engaged with concerns around declining child sex ratio for long $(5,12,13,14,15)$. One of the most widely agreed upon factors is the higher mortality rate amongst women as compared to men (16). However, what has emerged as the most revealing aspect of this discourse is the simple neglect and rejection of the girl child in families seeped in patriarchal norms and practices. The practice of female infanticide has been known to exist in certain regions of India like Punjab, Haryana, Rajasthan and parts of North-Western region (17). With the advent of new reproductive technologies and sex-selective abortion along with increasing neglect of their nutritional health and higher risk of sexual abuse, the vulnerabilities of a girl child have increased manifold (15).

The declining child sex ratio and the factors that have contributed to this negative trend is a reflection of larger problem of gender discrimination that plagues number of countries in the world, including India. A life cycle approach to a woman's life reveals a range of discriminatory practices, norms and even institutions that continue to restrain their freedom, choices and right to live as equal citizens of the state. The Indian state and judiciary have time and again taken cognizance of various forms of gender discrimination and have responded through number of policies, programmes, initiatives and judgements in that direction. Apart from enacting laws to ban pre-natal sex determination such as the PreConception and Pre-Natal Diagnostic Techniques (Prohibition of Sex Selection) Act (PCPNDT Act) 1994, amended in 2003, a number of initiatives like the
Laadli scheme, Stree Shakti project, Sukanya Samriddhi Yojana, Balika Samridhhi Yojana, Beti Bachao Beti Padhao and many more, have been launched by previous governments and the current one at national and state levels, to create awareness and provide support in both rural and urban areas. Beti Bachao and Beti Padhao (BBBP) an initiative of the central government which started in 2015, brings about the convergence of three ministries - Ministry of Health and Family Welfare, Ministry of Education and the Ministry of Women and Child Development to work on this issue. Its initial focus was on hundred districts with the lowest child sex ratio but it was later broadened to include all 640 districts of the country. The convergence of the BBBP is an ideal one reflecting a holistic approach yet to be seen in any other policy, programmes or schemes. The Ministry of Health and Family Welfare is responsible for the implementation of the PCPNDT Act. The Ministry of Education is invested with the responsibility of promoting girl-child education. Other than these ministries, Ministry of Home Affairs is also involved in evolving an understanding of the issue as crime against women.

A research study (2018-2020) conducted by us in the states of Haryana and Uttar Pradesh in order to examine the impact of the scheme on countering gender discrimination provided certain insights. In 2011, the state of Haryana was the worst performer in the context of Child Sex Ratio in India, recording a child sex ratio of 834 girls per 1000 boys. Uttar Pradesh had been 10th from the bottom recording a child sex ratio of 902 girls per 1000 boys. Child Sex Ratio in both the states is below the biological normal due to pre-birth elimination of female foetus and post birth girl child discrimination (18). Therefore, the states of Uttar Pradesh and Haryana depict some similarities of girl child discrimination tendencies. The sites selected were Mahendragarh in Haryana and Baghpat in Uttar Pradesh.

Since the scheme had been unfurled with commitment and passion in Haryana, we noted that there was a sense of ownership of the programme by the implementers and awareness amongst the general populace. A commitment to education of the girl child and publicly celebrating the girl children as role models, were a visible impact of the scheme. The implementation of the law, i.e. PCPNDT act, was also far more visible in Mahendragarh than in Baghpat. Social messaging and local initiatives highlighting value of girls were positive impact of the 
BBBP. In Baghpat, Uttar Pradesh the programme had not made its foray to the policy environment. In Mahendragarh the prevailing masculinist discourse in the community programmes in Panchayat meetings had undergone a transformation due to the BBBP. The value of the girl child or the right of daughters to be protected and to promote their education were some of the positives drawn from the programme and found mention in most discussions amongst male leaders at the local level. In terms of community participation, women in Haryana played an active role and had agency in negotiating changes in certain spheres. In Baghpat this agency was considerably muted and we were not able to note significant changes.

Comparing and contrasting the two districts in the two states, one can come to the conclusion that policy discourse impacts and brings about a shaping of societal attitude and mind-sets. There are however many other factors at play including social, political, economic and cultural issues which need to be studied in tandem.

The issue of gender discrimination present in the heinous practice of sex-selective abortion needs to move away from the binary distinction between girl child and women. It, in fact, requires a participatory community health approach which enables a societal understanding that the protection of daughters (Beti Bachao) is not just about preventing sexdetermination and sex-selective abortion.

It is also about providing safe and legal abortion services.

It requires participation of women in the community or at the panchayat level and frontline health workers who can be empowered in two aspects:

a) The felt needs of sexual and reproductive health of girls and women in the community to be assessed at the micro level and planning is to be done at their level.

b) The monitoring of health indicators is to be done periodically by using a bottom-up approach. Assistance and training to be provided to them in order to bring about community mobilization on women's health, gender equality, raising awareness on specific elements of the BBBP as well as ensuring its stringent implementation.

While the educating of daughters (Beti Padhao) emphasizes only on school education, there is a need for a sustained forward linkage of the scheme from school education to college education in terms of skill building, employability, breaking stereotypes about women's roles in society, involving women in sciences, permeating sciences with ideas of ethics and gender equality, multi-disciplinary research and encouraging women for leadership roles.

Looking at the positive impact of the BBBP, our recommendation is that it should not stop with awareness at the community or promoting education at school levels. It needs to be established as a community health perspective at the level of Higher Educational Institutions so that both young women and men who would be making fertility choices in their near future are empowered and aware about the value of the girl-child and women, about the significance of empowered and informed reproductive choices and the relevance of creating an egalitarian society. The ethos of community health contributing to the discourse of gender equality find scope within the context of the programme. This needs to be highlighted and imbibed at all levels in order to be able to counter gender discrimination which is reflected in sex ratio imbalance.

While in Mahendragarh (Haryana), the BBBP can be enriched with community participation and forwards linkages, enhancing its transformational impact on gender equality, in Baghpat (Uttar Pradesh) there could be certain lessons drawn from the Mahendragarh experience so that the first steps are initiated in order to bring about passion and commitment to implement the BBBP. This is not to say that all answers lie in a government programme but to emphasize on the positive impact of the policy discourse (BBBP) based on notions of community health and participation with gender sensitive elements. This may be considered as an effective strategy to bring about societal changes for countering gender discrimination.

\section{References}

1. Kulkarni, Purushottam M. (2019) Sex Ratio at Birth in India: Recent Trends and Patterns, UNFPA, New Delhi.

2. Sen, A. More than 100 Million Women are Missing, New York Review of Books. 1990; 20:61-66.

3. Coale, Ansley (1991). 'Excess female mortality and the balance of sexes in the population: An estimated number of missing females', Population and development Review, 1991;17(3):517-23.

4. Dubuc S, Sivia DS. Is sex ratio at birth an appropriate measure of prenatal sex selection? Findings of a theoretical model and its application to India. BMJ Glob Health. 2018;19;3(4):e000675. doi: 10.1136/bmjgh-2017-000675. PMID: 30057794; PMCID: PMC6058172.[PubMed]. 
5. Agnihotri, Satish. 'Survival of the girl child: tunnelling out of the Chakravyuha', Economic and Political Weekly.2003;4351-4360.

6. Das Gupta, M. and Bhat, P.N.M. (1995). 'Intensified gender bias in India: A consequence of fertility decline', Working paper No:2, Centre for Population and Development Studies, Harvard University.

7. Miller, B.D. (1981). The Endangered Sex, Cornell university press, Ithaca, New York.

8. Visaria, P. (1971). The Sex Ratio of the Population of India, Census Monograph No. 10, New Delhi, Office of the Registrar General

9. Guilmoto, C.Z. and S. Irudaya Rajan. 'Spatial Patterns of Fertility Transition sin Indian Districts', Population and Development Review.2001;27(4):713-38.

10. Guilmoto, Christophe Z. 'The sex ratio transition in Asia.' Population and Development Review 2009;35(3):519-549.

11. Nanda B, Ray N, Mukherjee R, Jairaj R. (2019) ' Gender Discrimination and Violence Against Women: Connecting the Dots of Declining Child Sex Ratio in India, Mainstream, LVII , 16 : New Delhi

12. Shiva, Meera (2002). 'Skirting the Issue: The Girl Child', in Seen but not Heard, New Delhi: Voluntary Health Association of India.
13. Siddhanta, Suddhasil \& Agnihotri, Satish \& Nandy, Debasish (2009). 'Sex Ratio Patterns Among the Scheduled Castes in India 1981-2001', SSRN Electronic Journal. $10.2139 /$ ssrn. 2733500

14. Patel, Vibhuti (2007). 'The Political Economy of Missing Girls in India', in Tulsi Patel (ed.) Sex-Selective Abortion in India: Gender. Society and New Reproductive Technologies, New Delhi: Sage Publications.

15. Nanda, Bijayalaxmi (2018). Sex-Selective Abortion and the State: Policies, Laws and Institutions in India, New Delhi: Shakti Books, Haranand Publications. $n$

16. Visaria, Leela. 'Two Child Norm: Normalizing the Vulnerable', Economic and Political Weekly, 2006;XLI(1):4148.

17. Oldenberg, P. 'Sex ratio, son preference and violence in India - A research note.' Economic and Political Weekly. 1992;27(49):2657.

18. Hatti, N., Sekher, T. V., \& Larsen, M. (2004). 'Lives at Risk. Declining Child Sex Ration in India', Lund Papers in Economic History, No. 93, Department of Economic History, Lund University. 